\title{
Anti-sepsia de mãos na indústria de carnes: avaliação da clorhexidina, triclosan e iodóforo na redução da contaminação microbiana em manipuladores
}

\author{
Hand hygiene in the meat industry: effect of chlorhexidine, triclosan and iodophor \\ on the reduction of microbial contamination among meat handlers
}

\author{
Viviane de Melo Litz ${ }^{1 *}$, Laura Beatriz Rodrigues ${ }^{2}$, Luciana Ruschel dos Santos ${ }^{2} \&$ Fernando Pilotto $^{3}$
}

\section{RESUMO}

A indústria da carne ocupa lugar de destaque na produção de alimentos e a adequada anti-sepsia das mãos dos manipuladores é etapa de fundamental importância do ponto de vista da segurança alimentar, já que elas podem veicular aos produtos em elaboração microrganismos deteriorantes e patogênicos. Com o objetivo de avaliar a ação dos princípios ativos clorhexidina, iodóforo e triclosan como anti-sépticos in vitro e nas condições de uso da indústria, submeteu-se três formulações comerciais ao teste de eficácia de desinfetantes e avaliação microbiológica em manipuladores de uma indústria frigorífica, a fim de verificar a redução da população microbiana das mãos a níveis aceitáveis. Os dados obtidos in vitro demonstraram que somente a clorhexidina foi eficaz em 30 segundos frente aos microrganismos testados. Na avaliação microbiológica, os antisépticos testados reduziram as contagens iniciais de mesófilos aeróbios e Staphylococcus sp. A análise de variância apontou a superioridade da clorhexidina tanto na redução da contagem de mesófilos aeróbios como de Staphylococcus sp. e que não houve diferença estatística entre iodóforo e triclosan.

Descritores: anti-sépticos, manipuladores, swab, clorhexidina, iodóforo, triclosan.

\section{ABSTRACT}

The meat industry has a major role to play in food production, and proper hand hygiene of meat handlers is extremely important for food safety, since improperly washed hands can contaminate products with spoilage and pathogenic microorganisms. In order to assess the in vitro activity of chlorhexidine, iodophor and triclosan as hand antiseptics among meat handlers, and also their activity under industrial conditions, three commercially available formulas were submitted to an efficacy test and microbiological assessment, so that the reduction of microbial counts could be reduced to acceptable levels. The in vitro data showed that only chlorhexidine was efficient in 30 seconds against known microorganisms. The microbiological assessment revealed that the analyzed antiseptics reduced the initial counts of aerobic mesophilic bacteria and of staphylococci. The analysis of variance demonstrated that chlorhexidine was efficacious in reducing the counts of aerobic mesophilic bacteria and of Staphylococcus sp., with no statistical difference between iodophor and triclosan.

Key words: antiseptics, handlers, swab, chlorhexidine, iodophor, triclosan. 


\section{INTRODUÇÃO}

Os alimentos estão expostos, durante sua elaboração, a uma série de perigos ou oportunidades de contaminação microbiana, que podem estar relacionadas a práticas inadequadas de processamento e de manipulação. A alta perecibilidade dos produtos de origem animal, dentre eles os derivados cárneos, faz com que seja fundamental a adoção de práticas adequadas de higiene e manipulação nos estabelecimentos [13]. A correta anti-sepsia das mãos dos manipuladores na indústria de carnes se constitui em uma das mais importantes etapas que influenciam na qualidade microbiológica dos alimentos produzidos, já que as mãos podem apresentar microrganismos deteriorantes e patogênicos, que precisam ser removidos a fim de evitar sua veiculação aos alimentos, prejudicando sua vida de prateleira ou oferecendo riscos potenciais aos consumidores $[1,6,9,14,15,17]$. Uma vez que não há padrões ou especificações para contagens microbianas em mãos de manipuladores de alimentos, são sugeridos como níveis aceitáveis de contaminação para as mãos contagens inferiores a $10^{4} \mathrm{UFC} / \mathrm{mão}$ para mesófilos aeróbios, $10^{2} \mathrm{UFC/mão} \mathrm{para} \mathrm{Staphylococcus}$ aureus e $10^{2}$ UFC/mão para Escherichia coli. [2]. Considerando a importância da adequada anti-sepsia das mãos, e tendo em vista a grande variedade de antisépticos comercializados com esta finalidade, o objetivo deste trabalho foi quantificar e avaliar a ação de alguns destes agentes, sendo as formulações a base de iodóforo, triclosan e clorhexidina selecionadas para esta pesquisa por serem largamente utilizadas na indústria de carnes.

\section{MATERIAIS E MÉTODOS}

Foram escolhidas três formulações comerciais prontas para uso, de três fabricantes diferentes, contendo os princípios ativos em avaliação:

Tratamento 1. Iodóforo: sabonete líquido a base de tensoativos não-iônicos, iodo a $0,1 \%$, emoliente e agente tamponante;

Tratamento 2. Triclosan: sabonete líquido tipo spray a base de lauril éter sulfato de sódio, codamida, mono propileno glicol e triclosan (Irgasan DP 300) a 0,1\%; Tratamento 3. Clorhexidina: sabonete líquido a base de clorhexidina a $2 \%$.

Inicialmente os anti-sépticos foram testados frente a um pool de bactérias previamente incubadas (Bacillus cereus, Enterobacter aerogenes, Enterococcus faecalis, Escherichia coli, Pseudomonas aeruginosa, Salmonella Typhimurium, Staphylococcus aureus, Staphylococcus epidermidis), nos tempos de contato de 30 segundos, 1 minuto, 5 minutos e 10 minutos [7].

Para a avaliação dos anti-sépticos nas condições de uso na indústria, o experimento foi realizado no Frigorífico da Cotripal Agropecuária Cooperativa, com 10 funcionários selecionados das diferentes áreas de produção da empresa. Efetuou-se a coleta por meio de swabs estéreis, de rayon ${ }^{1}$, usando um aplicador de plástico [2,11]. Tomou-se a mão esquerda para amostragem da pele antes da higienização, denominando-a amostra controle. No momento da coleta, umedeceu-se a mão com água destilada estéril, friccionando-se o swab de forma angular, com movimentos giratórios, numa área correspondente às superfícies das palmas e bordas das mãos, partindo da região dos punhos, iniciando-se da parte inferior das palmas até a extremidade dos dedos e voltando ao punho, repetindo-se este procedimento três vezes na direção de cada dedo. O movimento nas bordas da mão foram em um deslizar tipo vai-vem, avançando em um dos lados da mão onde as linhas dos punhos se iniciam, passando depois entre os dedos e finalizando no outro lado da mão, encontrando-se de novo com as linhas dos punhos. Em seguida, os swabs coletados foram transferidos para tubos plásticos contendo $10 \mathrm{~mL}$ de solução tampão-neutralizante estéril, sendo que esse tubo representou a primeira diluição.

Posteriormente, o manipulador fez a higienização das mãos com uma das formulações comerciais, esfregando-as por 30 segundos e enxaguando com água destilada estéril, sem secar. Tomou-se então a mão direita para coleta do swab como descrito acima, representando a pele após a higienização e sendo denominada tratamento 1 (iodóforo). As análises microbiológicas foram realizadas no mesmo dia. $\mathrm{O}$ mesmo procedimento foi adotado para as outras formulações comerciais nas semanas subseqüentes, denominando-se a amostragem da mão antes da anti-sepsia como amostra controle e, depois da anti-sepsia, como tratamento 2 (triclosan) e tratamento 3 (clorhexidina).

As determinações microbiológicas foram realizadas em duplicata e compreenderam as seguintes análises: contagem de aeróbios mesófilos, contagem de Staphylococcus sp., contagem de coliformes totais e contagem de coliformes termotolerantes [8,12].

A avaliação dos anti-sépticos foi realizada através da determinação do número médio de redu- 
ções decimais da população microbiana das mãos dos dez manipuladores após cada tratamento. Para tanto, houve a necessidade de transformar os resultados obtidos em logaritmos de base 10. A análise de variância foi aplicada às médias de reduções decimais dos resultados das contagens microbiológicas e as diferenças das médias foram analisadas pelo Teste de Tukey a 5\% de significância.

\section{RESULTADOS}

A Tabela 1 demonstra a atividade dos antisépticos frente ao "pool" de microrganismos conhecidos nos tempos considerados. A avaliação in vitro demonstrou que apenas a clorhexidina foi eficaz frente aos microrganismos testados no tempo de 30 segundos. O iodóforo foi eficaz somente no décimo minuto de contato e o triclosan não foi eficiente nos tempos considerados.

As Tabelas 2, 3 e 4 demonstram as médias das contagens microbiológicas das mãos dos manipuladores antes e após a anti-sepsia com os produtos em estudo. As contagens iniciais das mãos antes da anti-sepsia (amostras controle) variaram de 8,45.10² UFC/mão a $1,44.10^{6} \mathrm{UFC/mão} \mathrm{para} \mathrm{os} \mathrm{mesófilos}$

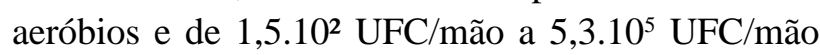
para os Staphylococcus sp. Bactérias do grupo coliforme não foram encontradas.

\section{DISCUSSÃO}

Os resultados absolutos das tabelas mencionadas demonstram que as contagens de microrganismos foram reduzidas após os tratamentos com os anti-sépticos. Para a contagem de mesófilos aeróbios, os níveis inferiores a $10^{4} \mathrm{UFC} /$ mão considerados seguros foram alcançados em 8 dos 10 manipuladores com os tratamento 1 (iodóforo) e com tratamento 2 (triclosan) e em 9 dos 10 manipuladores com o tratamento 3 (clorhexidina). Nesse trabalho não foram tipificados os Staphylococcus sp. para verificar se eram ou não coagulase positivos. Tendo em vista a existência de estafilococos coagulase negativo produtores

Tabela 1. Resultados das atividades dos anti-sépticos testados frente a um pool de bactérias*.

\begin{tabular}{lcccc}
\hline & \multicolumn{5}{c}{ Tempo } \\
\cline { 2 - 5 } Anti-séptico & $30 \mathrm{~s}$ & $1 \mathrm{~min}$ & $5 \mathrm{~min}$ & $10 \mathrm{~min}$ \\
\hline lodóforo & + & + & + & - \\
Triclosan & + & + & + & + \\
Clorhexidina & - & - & - & - \\
\hline
\end{tabular}

(-) Anti-séptico eficaz no tempo indicado: ausência de crescimento microbiano. (+) Anti-séptico não eficaz no tempo indicado: presença de crescimento microbiano. "Bacillus cereus, Enterobacter aerogenes, Enterococcus faecalis, Escherichia coli, Pseudomonas aeruginosa, Salmonella Typhimurium, Staphylococcus aureus, Staphylococcus epidermidis.

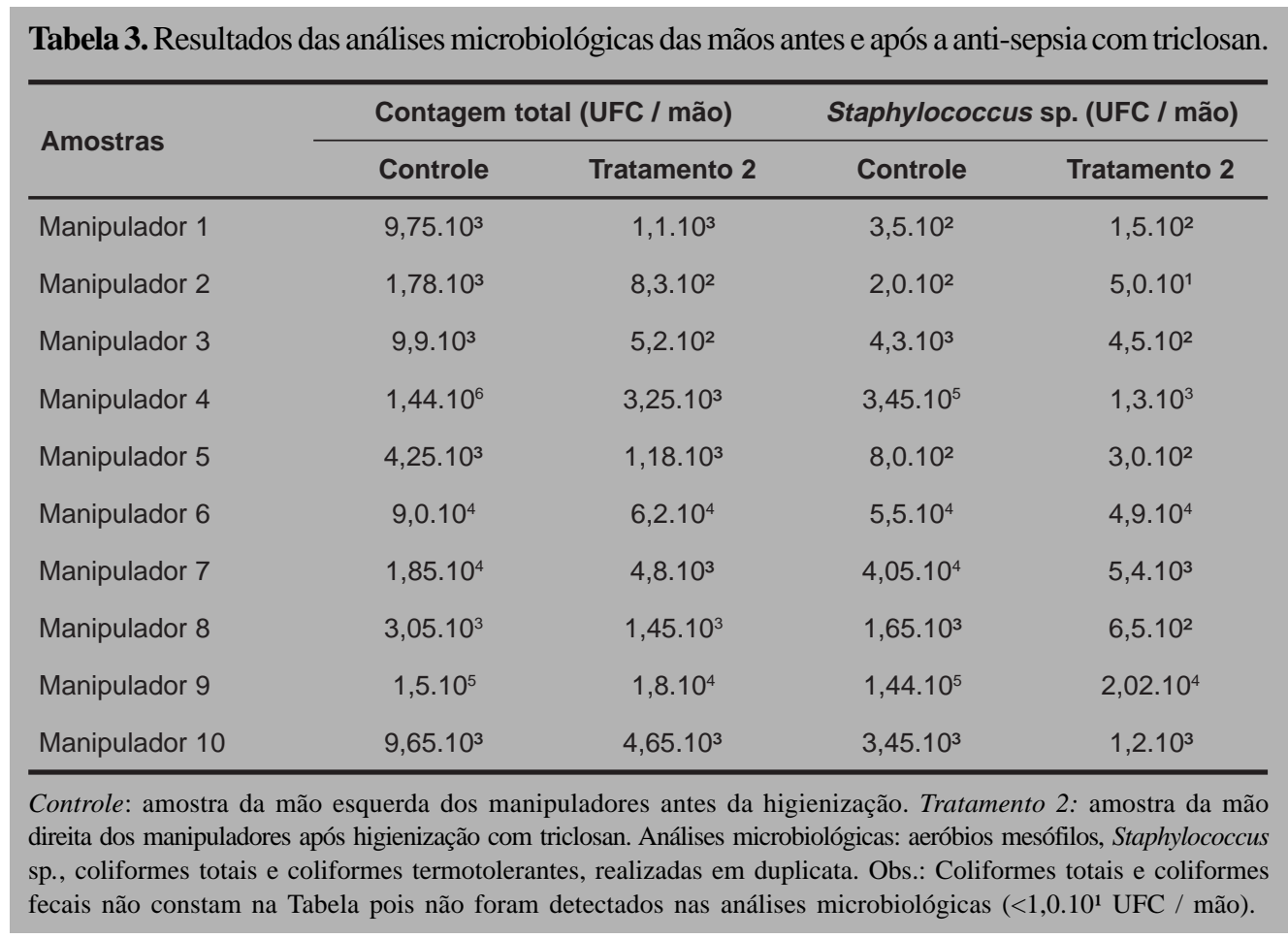


Tabela 2. Resultados das análises microbiológicas das mãos antes e após a anti-sepsia com iodóforo.

\begin{tabular}{lcccc}
\hline \multirow{2}{*}{ Amostras } & \multicolumn{2}{c}{ Contagem total (UFC / mão) } & \multicolumn{2}{c}{ Staphylococcus sp. (UFC / mão) } \\
\cline { 2 - 5 } & Controle & Tratamento 1 & Controle & Tratamento 1 \\
\hline Manipulador 1 & $7,1.10^{3}$ & $2,4.10^{3}$ & $1,41.10^{4}$ & $9,0.10^{2}$ \\
Manipulador 2 & $6,8.10^{4}$ & $4,5.10^{3}$ & $8,25.10^{4}$ & $4,25.10^{3}$ \\
Manipulador 3 & $8,5.10^{3}$ & $1,65.10^{3}$ & $2,0.10^{3}$ & $9,0.10^{2}$ \\
Manipulador 4 & $4,45.10^{4}$ & $1,8.10^{2}$ & $2,05.10^{3}$ & $1,0.10^{2}$ \\
Manipulador 5 & $3,7.10^{3}$ & $1,75.10^{3}$ & $1,0.10^{3}$ & $4,5.10^{2}$ \\
Manipulador 6 & $4,55.10^{4}$ & $3,7.10^{3}$ & $8,0.10^{4}$ & $5,5.10^{2}$ \\
Manipulador 7 & $3,8.10^{4}$ & $2,75.10^{4}$ & $1,4.10^{4}$ & $6,2.10^{3}$ \\
Manipulador 8 & $8,45.10^{2}$ & $7,85.10^{2}$ & $1,5.10^{2}$ & $1,0.10^{2}$ \\
Manipulador 9 & $1,9.10^{5}$ & $3,25.10^{4}$ & $5,3.10^{5}$ & $5,6.10^{4}$ \\
Manipulador 10 & $1,15.10^{5}$ & $5,85.10^{3}$ & $1,3.10^{5}$ & $4,05.10^{2}$ \\
\hline Conte:
\end{tabular}

Controle: amostra da mão esquerda dos manipuladores antes da higienização. Tratamento 1: amostra da mão direita dos manipuladores após higienização com iodóforo. Análises microbiológicas: aeróbios mesófilos, Staphylococcus sp., coliformes totais e coliformes termotolerantes, realizadas em duplicata. Obs.: Bactérias do grupo coliforme não constam na tabela pois não foram detectados nas análises microbiológicas $\left(<1,0.10^{1}\right.$ UFC / mão).

Tabela 4. Resultados das análises microbiológicas das mãos antes e após a anti-sepsia com clorhexidina.

\begin{tabular}{|c|c|c|c|c|}
\hline \multirow{2}{*}{ Amostras } & \multicolumn{2}{|c|}{ Contagem total (UFC / mão) } & \multicolumn{2}{|c|}{ Staphylococcus sp. (UFC / mão) } \\
\hline & Controle & Tratamento 3 & Controle & Tratamento 3 \\
\hline Manipulador 1 & $1,92.10^{4}$ & $<1,0.10^{1}$ & $1,5.10^{2}$ & $<1,0.10^{2}$ \\
\hline Manipulador 2 & $9,55.10^{2}$ & $5,0.10^{1}$ & $5,0.10^{2}$ & $5,0.10^{1}$ \\
\hline Manipulador 3 & $5,15.10^{3}$ & $3,0.10^{1}$ & $2,85.10^{3}$ & $<1,0.10^{2}$ \\
\hline Manipulador 4 & $1,81.10^{5}$ & $1,09.10^{3}$ & $5,45.10^{3}$ & $5,0.10^{1}$ \\
\hline Manipulador 5 & $1,84.10^{3}$ & $<1,0.10^{1}$ & $4,5.10^{2}$ & $<1,0.10^{2}$ \\
\hline Manipulador 6 & $9,15.10^{4}$ & $9,0.10^{2}$ & $5,6.10^{4}$ & $5,0.10^{2}$ \\
\hline Manipulador 7 & $6,5.10^{4}$ & $4,8.10^{2}$ & $2,3.10^{4}$ & $2,5.10^{2}$ \\
\hline Manipulador 8 & $1,38.10^{4}$ & $1,1.10^{2}$ & $7,0.10^{3}$ & $5,0.10^{1}$ \\
\hline Manipulador 9 & $8,4.10^{4}$ & $1,72.10^{4}$ & $6,0.10^{4}$ & $6,0.10^{3}$ \\
\hline Manipulador 10 & $2,02.10^{4}$ & $1,55.10^{3}$ & $1,07.10^{4}$ & $1,7.10^{3}$ \\
\hline
\end{tabular}

de toxinas que representam risco à saúde pública e não havendo padrões recomendados para estes microrganismos, consideraram-se os níveis inferiores a $10^{2}$ UFC/mão para $S$. aureus para a discussão dos dados [2,3]. De acordo com os resultados obtidos, esses níveis não foram atingidos por nenhum dos manipuladores com o tratamento 1 , somente em 1 dos manipuladores com o tratamento 2 e em 6 manipuladores com o tratamento 3 .

A comparação das médias de reduções decimais na contagem total e Staphylococcus sp. pela ação dos anti-sépticos está demonstrada na Tabela 5. A clorhexidina foi superior em relação aos outros tratamentos na redução da contagem total de mesófilos 


\begin{tabular}{|c|c|c|}
\hline \multirow{2}{*}{ Tratamentos } & $\begin{array}{c}\text { Contagem de } \\
\text { esófilos aeróbios }\end{array}$ & Staphylococcus sp. \\
\hline & Média (1)(2) & Média ${ }^{(1)(2)}$ \\
\hline Clorhexidina (Tratamento 3) & $2,13 a$ & 1,928 a \\
\hline lodóforo (Tratamento 1) & $0,839 \mathrm{bc}$ & $1,067 \mathrm{bc}$ \\
\hline Triclosan (Tratamento 2) & $0,808 \mathrm{c}$ & $0,744 \mathrm{c}$ \\
\hline
\end{tabular}

e de Staphylococcus sp., enquanto o iodóforo e o triclosan não demonstraram diferença estatística entre eles $(\mathrm{p}<0,05)$.

O desempenho da clorhexidina in vitro concorda com as literaturas que mencionam sua ação rápida, tanto frente a microrganismos Gram positivos como para Gram negativos [4,10]. A realidade nas indústrias frigoríficas aponta para a dificuldade de se conseguir que os manipuladores de alimentos higienizem suas mãos esfregando-as por tempo superior a 30 segundos, que seria o tempo de contato com o anti-séptico, antes de submetê-las ao enxágüe. Assim sendo, é importante que o anti-séptico em uso comece a agir no menor tempo possível.

No presente trabalho não foram detectadas bactérias do grupo coliforme, em contraposição à maioria das pesquisas que identificou coliformes em mãos de manipuladores no exercício de suas atividades $[5,9,15,16]$. No caso desse trabalho, a coleta foi efetuada antes dos manipuladores ingressarem nas áreas de processamento e o resultado de ausência concorda com a literatura que aponta os coliformes como bactérias transitórias, que geralmente estão ausentes da pele das mãos [1,6].

Os níveis aceitáveis de contaminação para as mãos de manipuladores talvez fossem alcançados através do procedimento duplo de higienização das mãos, que não foi utilizado nessa pesquisa. $\mathrm{O}$ procedimento duplo é recomendado nas seguintes situações: troca de função, após o uso de sanitários, após executar limpeza de sanitários e locais infectados e ao entrar na área de processamento, situação essa que foi abordada nesta pesquisa. O procedimento consiste resumidamente em higienização com sabão, esfrega criteriosa com auxílio de escova, seguida de enxágüe, com mais uma esfrega com sabão, sem escova, enxágüe e aplicação de anti-séptico [2]. Como nessa pesquisa trabalhou-se com sabonetes líquidos que já possuíam anti-sépticos na sua constituição, a realização de duas esfregas seguidas de enxágüe com os produtos talvez reduzisse a contaminação satisfatoriamente.

A anti-sepsia das mãos se constitui, portanto, em aspecto fundamental para a redução da microbiota presente nas mãos de manipuladores de alimentos na indústria de carnes e, conseqüentemente para a garantia da segurança alimentar. As análises microbiológicas demonstraram que nenhum dos anti-sépticos avaliados foi capaz de deixar as mãos livres dos microrganismos pesquisados, porém a escolha do princípio ativo a ser utilizado nessa etapa deve se basear, sempre que possível, em avaliações práticas. A partir dos resultados obtidos, sugere-se a avaliação do procedimento duplo de higienização das mãos dos manipuladores antes do ingresso nas áreas de produção, a fim de verificar se a anti-sepsia, seguida de enxágüe, realizada com esses princípios ativos por duas vezes, seria capaz de reduzir a contaminação das mãos aos níveis recomendados.

\section{CONCLUSÃO}

$\mathrm{Na}$ avaliação in vitro, somente a clorhexidina mostrou-se eficaz contra microrganismos selecionados no tempo de 30 segundos, período aproximado da realidade do processo de anti-sepsia na indústria de carnes. Aplicando-se o tratamento estatístico para a avaliação da eficácia dos princípios ativos, as médias de reduções decimais foram superiores com a clorhexidina para mesófilos aeróbios e Staphylococcus sp., e não houve diferença estatística entre o triclosan e o iodóforo.

\section{NOTA INFORMATIVA}

${ }^{1}$ SRK - swab rinse kit - 902C, Copan ${ }^{\circledR}$. 


\section{REFERÊNCIAS}

1 Almemda R.C.C., Kuaye A.Y., Serrano A.M. \& Almeida P.F. 1995. Avaliação e controle da qualidade microbiológica de mãos de manipuladores de alimentos. Revista de Saúde Pública, 29. Disponível em: 〈http:// www.scielo.br/scielo.php〉. Acessado em 03/2006.

2 Andrade N.J. 2005. Metodologias para avaliar condições higiênicas de ambientes de processamento de alimentos. In: XIII Congresso Brasileiro de Microbiologia (Santos, Brasil). 1 CD-ROM.

3 Andrade N.J. 2005. Metodologias convencionais para análises microbiológicas de equipamentos, utensílios e manipuladores na indústria de alimentos. In: XIII Congresso Brasileiro de Microbiologia (Santos, Brasil). 1 CD-ROM.

4 Andrade N.J. \& Macêdo J.A. 1996. Higienização na indústria de alimentos. São Paulo: Varela, 182p.

5 Andrade N.J., Silva R.M.M. \& Brabes K.C.S. 2003. Avaliação das condições microbiológicas em unidades de alimentação e nutrição. Ciência Agrotecnológica. 27: 590-596.

6 Blom B.C. \& Pedrosa T.M.G. 1997. Lavagem de mãos. In: Couto R.C., Pedrosa T.M.G. \& Nogueira J.M. (Eds). Infecção hospitalar: epidemiologia e controle. Rio de Janeiro: Medsi, pp.253-263.

7 BRASIL. Portaria n. 101 de 11 de agosto de 1993. Aprova e oficializa os métodos analíticos para controle de produtos de origem animal e seus ingredientes (métodos microbiológicos). Diário Oficial da República Federativa do Brasil, Brasília, 17 ago. 1993. Seção I. Disponível em: 〈http://extranet.agricultura.gov.br/sislegis-consulta〉. Acessado em 05/2006.

8 BRASIL. Instrução Normativa n. 62 de 26 de agosto de 2003. Oficializa os métodos analíticos oficiais para análises microbiológicas para controle de produtos de origem animal e água. Diário Oficial da República Federativa do Brasil, Brasília, 18 set. 2003. Seção I. Disponível em:< http://extranet.agricultura.gov.br/sislegis-consulta>. Acessado em 04/2006.

9 Cardoso R.C.V., Chaves J.B.P., Andrade N.J. \& Teixeira M.A. 1996. Avaliação da eficiência de agentes sanificantes para mãos de manipuladores de alimentos em serviços de refeição coletiva. Higiene Alimentar. 10: 17-22.

10 Denton G.D. 2001. Chlorhexidine. In: Block S.S. (Ed). Disinfection, sterilization and preservation. 5th edn. Philadelphia: Lippincott Williams e Wilkins, pp.321-333.

11 Evancho G.M., Sveum W.H., Moberg L.J \& Frank J.F. 2001. Microbiological monitoring of the food processing environment. In: Downes F.P. \& Ito K. (Eds). Compendium of methods for the microbiological examination of foods. 4th edn. Washington: American Public Health Association, pp.25-35.

12 Kornacki J.L. \& Johnson J.L. 2001. Enterobacteriaceae, coliforms, and Escherichia coli as quality and safety indicators. In: Downes F.P. \& Ito K. (Eds). Compendium of methods for the microbiological examination of foods. 4th edn. Washington: American Public Health Association, pp.69-82.

13 Pardi M.C., Santos I.F., Souza E.R \& Pardi H.S. 2001. Ciência, Higiene e Tecnologia da Carne. 2 ed. v.1. Goiânia: Ed. UFG, 623p.

14 Silva Jr E.A. 1997. Manual de controle higiênico-sanitário em alimentos. 2 ed. São Paulo: Varela, 385p.

15 Siqueira Jr. W.M., Careli R. T., Andrade N.J. \& Mendonça R.C.S. 2004. Qualidade microbiológica de equipamentos, utensílios e manipuladores de uma indústria de processamento de carnes. Revista Nacional da Carne. Disponível em: <http:// www.dipemar.com.br/carne/326/materia_especial2_carne.htm>. Acessado em 12/2005.

16 Souza E.L., Silva C.A. \& Sousa C.P. 2004. Qualidade sanitária de equipamentos, superfícies, água e mãos de manipuladores de alguns estabelecimentos que comercializam alimentos na cidade de João Pessoa, PB. Higiene Alimentar.18: 98-102.

17 Tomazelli I.B. \& Santos I.R. 2000. Pesquisa sobre a eficiência do ácido peracético, álcool iodado e clorhexidina na desinfecção de mãos. Higiene Alimentar. 14: 48-54. 